\title{
Wireless Capsule Endoscopy for the Detection of Small Bowel Diseases in HIV-1-Infected Patients
}

\author{
M. Oette ${ }^{1}$, A. Stelzer ${ }^{2}$, K. Göbels ${ }^{3}$, M. Wettstein ${ }^{4}$, A. Sagir ${ }^{3}$, T. Feldt ${ }^{3}$, D. Häussinger ${ }^{3}$ \\ ${ }^{1}$ Klinik für Allgemeine Innere Medizin, Gastroenterologie und Infektiologie, Krankenhaus der Augustinerinnen Köln, Germany \\ ${ }^{2}$ Klinik für Gastroenterologie und Hepatologie, Universitätsklinikum Köln, Germany \\ ${ }^{3}$ Klinik für Gastroenterologie, Hepatologie und Infektiologie, Universitätsklinikum Düsseldorf, Germany \\ 4. Medizinische Klinik, Klinikum Passau, Germany
}

\begin{abstract}
Background and Aims: In HIV-infected patients, manifestations of the disease are common in the gastrointestinal tract. The objective of our study was to evaluate the diagnostic yield of the Given ${ }^{\circledR}$ Video Capsule System (Given Imaging, Yoqneam, Israel) in these patients.

Methods: After exclusion of GI-tract stenosis by anamnestic exploration, 49 patients were included into the study. Stratification: Group A ( $\mathrm{n}=19)$ : HIV-positive, $\mathrm{CD}_{4}$ cell count $<200 / \mu \mathrm{l}$, gastrointestinal symptoms present. Group B: HIV-positive, $\mathrm{CD}_{4}<200 / \mu \mathrm{l}$, without gastrointestinal symptoms ( $\mathrm{n}=19$ Group) C: healthy volunteers $(\mathrm{n}=11)$.

Results: In group A there was a total of 30 pathological findings, 15 of which with therapeutic implications. In group $\mathrm{B}$, there was a total of 22 pathological findings, 5 relevant for therapy. In group $\mathrm{C}$ there was a total of 13 pathological findings, 3 with therapeutic relevance. In $89 \%$ (group A) vs. $26 \%$ (group B), pathological findings were detected distal the ligament of Treitz ( $p=0.001)$. All capsules were recovered without complications after 12 to $96 \mathrm{~h}$ from the stool.

Conclusion: Wireless capsule endoscopy of the small intestine should be considered for HIV-infected patients with marked immunosuppression and gastrointestinal symptoms.
\end{abstract}

\section{INTRODUCTION}

The lymphoid tissue of the gut harbors most of the Tlymphocytes of the body and plays an important role as the first line of defense against viral, bacterial, parasitic and fungal pathogens $[1,2]$. Therefore, the gastrointestinal tract is particularly susceptible to infections resulting from $\mathrm{CD}_{4}$ cell depletion associated with HIV infection [3]. Since the introduction of highly active antiretroviral therapy (HAART), the frequency of opportunistic infections of the gastrointestinal tract has fallen dramatically. However, despite the administration of HAART there are still patients developing opportunistic infections of the gastrointestinal tract. Depending on the study population, the incidence is about $10 \%$ [4]. Low adherence, resistance to HAART and low bioavailability of antiretroviral drugs may play an important role in the pathophysiology of opportunistic infections in the HAART era. Furthermore, many protease inhibitors cause diarrhea as a side effect [5]. Among the infectious agents causing gastrointestinal abnormalities in HIV patients are: Salmonella spp., atypical Mycobacteria such as Mycobacterium avium intracellulare (MAI), Escherichia coli, Shigella spp. and Campylobacter spp., Candida spp., Cytomegalovirus (CMV) and Herpes simplex virus (HSV) [5, 6, 7]. Cryptosporidium, Microsporidium and Giardia are distributed worldwide. Entamoeba histolytica and Strongyloides stercoralis are mainly of tropical origin, but can be transmitted by sexual contact [5]. HIV infected patients without gastrointestinal symptoms often have minor abnormalities of villous architecture, characteristically a mild villous atrophy associated with either crypt hypoplasia or hyperplasia. To a lesser extent, these changes are seen in HIV-negative individuals as well. Invasive diagnostic procedures such as endoscopy are necessary for the diagnosis of gastrointestinal disorders, but most part of the small bowel until recently was not accessible to conventional endoscopy. The objective of our study was to evaluate the diagnostic yield of the Given ${ }^{\circledR}$ Video Capsule System (Given Imaging, Yoqneam, Israel) in HIV-positive patients with and without gastrointestinal symptoms and its therapeutic implications. The wireless endoscopy is meanwhile well established as a diagnostic tool in occult gastrointestinal bleeding when colonoscopy and gastro-duodenoscopy fail to identify the bleeding site.

\section{Patient Characterstics And Methods}

Between March 2002 and December 2004, 49 patients were included in our study prospectively and were divided into three groups. Group A consisted of HIVpositive patients with a $\mathrm{CD}_{4}$ cell count of $<200 / \mu \mathrm{l}$ and gastrointestinal symptoms such as diarrhea or abdominal pain $[\mathrm{n}=19$, age $45.7 \pm 9.8$ years (range 31 61), m:f 16:3, $\mathrm{CD}_{4}$ cells $78.1 \pm 59.9 / \mu \mathrm{l}$ (range 1-187)]. Group B consisted of HIV-positive patients with a $\mathrm{CD}_{4}$ cell count $<200 / \mu \mathrm{l}$, but without GI symptoms [n $=19$, age $43.7 \pm 9.7$ years (range 30-63), m:f 15:4, $\mathrm{CD}_{4}$ cells $\left.118.3 \pm 51.9 / \mu \mathrm{l}(10-196)\right]$. Group C were healthy volunteers $(\mathrm{n}=11$, age $36.8 \pm 4.2$ years (range 31-44), m:f 6:5) without any gastrointestinal symptoms.

All patients ingested the capsule after an overnight fast, without a complete colon preparation. Patients 


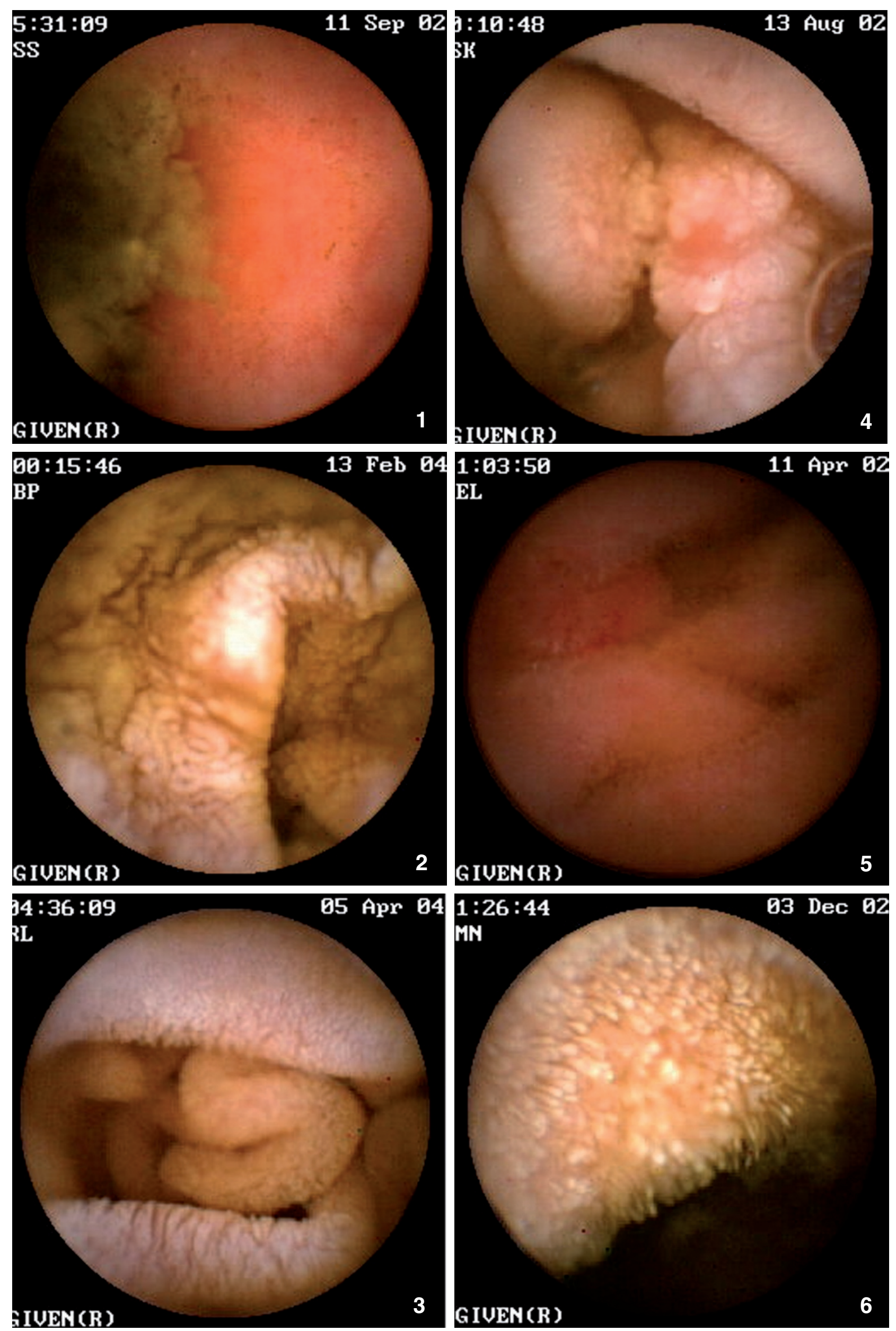


Table 1. Comparsion of the groups A, B and C. Group A: HIV positive, $\mathrm{CD}_{4}$ cell count $<200 / \mu$, gastrointestinal symptoms present. Group B: HIV positive, $\mathrm{CD}_{4}<200 / \mu$ l, without gastrointestinal symptoms. Group C: healthy volunteers.

\begin{tabular}{l|c|c|c|c|c|c}
\hline Group & $\begin{array}{c}\mathrm{n} \\
(\mathrm{m} / \mathrm{f})\end{array}$ & $\begin{array}{c}\text { Age } \\
\text { (year) }\end{array}$ & $\begin{array}{c}\mathrm{CD}_{4} \text { cell } \\
\text { count }(/ \mu \mathrm{l})\end{array}$ & $\begin{array}{c}\text { Number of } \\
\text { pathological } \\
\text { findings }\end{array}$ & $\begin{array}{c}\text { Pathological findings } \\
\text { proximal of the ligament } \\
\text { of Treitz }\end{array}$ & $\begin{array}{c}\text { Pathological findings } \\
\text { distal of the ligament } \\
\text { of Treitz }\end{array}$ \\
\hline $\begin{array}{l}\text { A } \\
\text { (HIV-positive) }\end{array}$ & $\begin{array}{c}19 \\
(16 / 3)\end{array}$ & $\begin{array}{c}46 \pm 10 \\
(31-61)\end{array}$ & $\begin{array}{c}78 \pm 60 \\
(1-187)\end{array}$ & 30 & $13(68 \%)$ & $17(89 \%)$ \\
\hline $\begin{array}{l}\text { B } \\
\text { (HIV-positive) }\end{array}$ & $\begin{array}{c}19 \\
(15 / 4)\end{array}$ & $\begin{array}{c}44 \pm 10 \\
(30-63)\end{array}$ & $\begin{array}{c}118 \pm 52 \\
(10-196)\end{array}$ & 22 & $17(89 \%)$ & $5(26 \%)$ \\
\hline C & 11 & $37 \pm 4$ & - & 13 & $8(73 \%)$ & $5(45 \%)$ \\
\hline
\end{tabular}

Fisher's exact test:

Pathological findings proximal of the ligament of Treitz:

Group A vs Group B; p $=0.232$

Group A vs Croup C; p $=1.000$

Group B vs Group C; p $=0.327$

were excluded if they had a history of bowel obstruction, abdominal operation, diabetes, pacemaker implantation or pregnancy. Patients ingested the capsule in the morning and remained in the clinic throughout the recording. All patients swallowed the capsule without problems and the procedure was well tolerated. They were allowed to drink clear fluids at 2 hours and to consume a light meal at 4 hours after ingestion of the capsule. The recorder was disconnected at about 8 hours after the beginning of the study. The patients were requested to verify the natural excretion of the capsule in the stool.

The Given M2A video capsule system (Given Imaging Ltd., Yoqneam, Israel) is a new method of direct visualization of the small bowel that provides noninvasive examination of areas of the gut that are not accessible through conventional endoscopy. It allows the visual investigation of the small bowel.

The study received approval by the local institutional review board, informed written consent was obtained by the participants.

\section{RESULTS}

The procedure was well tolerated and there were no complications. All capsules were recovered after 12 to $96 \mathrm{~h}$ in the stool. In group A $\left[\mathrm{CD}_{4}\right.$ cell count $<200 / \mu \mathrm{l}$ with gastrointestinal symptoms] the pathological findings were (n): Villous atrophy (6), antrum gastritis (5),

Fig. 1. Strongyloides stercoralis.

Fig. 2. Mycobacterium avium infection.,

Fig. 3. Villous atrophy.

Fig. 4. Ulcerative jejunitis.

Fig. 5. Kaposi sarcoma.

Fig. 6. Lymphangiectatic villi.
Pathological findings distal of the ligament of Treitz :

Group A vs Group B; p $=0.001$

Group A vs Croup C; $\mathrm{p}=0.028$

Group B vs Group C; p $=0.425$

ulcerative jejunitis (3), apthous jejunal lesion (2), brunneromas (2), jejunal Kaposi sarcoma (2), aphthous duodenal lesion (1) bulbitis (1), duodenal mucosal ulcer (1), follicular hyperplasia in terminal ileum (1), gastral mucosal ulcer (1), jejunal angiodysplasia (1), jejunal mycobacteriosis (1), jejunitis (1), reflux esophagitis (1), and Strongyloides stercoralis infection (1). Twelve patients had lymphangiectatic villi of the small intestine. In group A there was a total of 30 pathological results, 17 of these distal of the ligament of Treitz and 15 with therapeutic relevance. The diagnosis was accomplished by capsule endoscopy in 9 cases, where regular endoscopic evaluation would not have reached the site within the small intestine. In four cases the capsule did not pass the ileocoecal valve within the recorded time period due to reduced peristalsis.

In group B $\left[\mathrm{CD}_{4}\right.$ cell count $<200 / \mu$ l without GI symptoms] the following diagnoses were found (n): Antrum gastritis (4), gastric mucosal ulcer (4), duodenitis (3), reflux esophagitis (2), villous atrophy (2), brunneroma (1), colitis (1), duodenal mucosal ulcer (1), follicular hyperplasia within the terminal ileum (1), jejunal polyp (1), jejunitis (1), and suspected jejunal angiodysplasia (1). Six patients had lymphangiectatic villi in the small intestine. In group B, there was a total of 22 pathological findings, 5 of these distal of the ligament of Treitz and 5 with therapeutic relevance. Two patients had no pathological findings. In seven patients the capsule did not reach the ileocoecal valve within the recording period. In group B there the number of patients with lymphangiectatic villi and villous atrophy was lower as compared to group A (6 vs. 12$)$.

Finally, in group C [healthy volunteers] we found antrum gastritis (3), brunneromas (2), bulbitis (1), hypertensive gastropathy (1), ileitis (1), jejunal lipoma (1), jejunal polyp (1), pseudodiverticulum (1), suspected jejunal angiodysplasias (1), villous atrophy (1). Sporadic lymphangiectatic villi were seen in five patients. In group $C$ there were a total of 13 pathological results, 5 of these distal to the ligament of Treitz and 3 with therapeutic relevance (suspected jejunal angiodysplasia 
(1), jejunal polyp (1), ileitis (1). In one case the capsule did not reach the coecum during the examination.

\section{DISCUSSION}

Opportunistic infections and tumors of the gastrointestinal tract play an important role in clinical management of AIDS patients. The data presented in this study show that capsule endoscopy reveals a substantial variety of manifestations in the small bowel in HIV-positive patients with advanced immunosuppression. There were significantly more pathological findings distal of the ligament of Treitz in the group presenting with gastrointestinal symptoms (group A) than in the group B without gastrointestinal symptoms, in particular more severe findings like Kaposi sarcoma, ulcerative jejunitis due to CMV-infection, aphthous jejunal lesions, jejunal mycobacteriosis, Strongyloides stercoralis infection and jejunitis. This was valid especially for patients with $\mathrm{CD}_{4}$ cell count less than $100 / \mu \mathrm{l}$. Accordingly, therapeutic implications were more frequent in group A compared to group B patients. The number of pathological findings proximal of the ligament of Treitz and the total amount of findings are nearly identical in both HIV positive groups.

Interestingly, group C (healthy volunteers) showed several unexpected pathological findings. The small intestine might harbour certain conditions, which are beyond the reach of conventional diagnostic procedures and therefore there are certain conditions where it is hard to distinguish between normal and pathological findings. To confirm these findings, further investigations with the wireless capsule endoscopy should follow to investigate the small bowel under physiological conditions. Despite the absence of underlying HIVdisease in group C, the pathological findings of the small intestine like suspected jejunal angiodysplasias, jejunal polyp, ileitis, villous atrophy were similar as in group B.

Our study shows that capsule endoscopy is well tolerated and provides diagnostic information of the small intestine, which cannot be obtained by conventional endoscopy. The quantitative amount of pathological findings was comparable in both HIV positive groups, however, there were more severe pathological findings in the group with further progressed disease.

Several limitations of the study should be taken into account. Firstly, the sample size is small and thus may not be generalized for the whole HIV-infected population. Secondly, due to the cost of the capsules, the technique is not suitable in settings with limited resources. Moreover, as contemporary antiretroviral therapy is capable of controlling clinical manifestations of immunosuppression, the findings of the study may only be valid for a small subgroup of HIV- patients (so called late presenters without antiviral treatment). Finally, unspecific findings of capsule endoscopy may not be regarded as HIV-associated disease. Further studies are necessary to clarify the relevance of the spectrum of pathological results.

Despite limited size of study population, we could show that wireless capsule endoscopy of the small intestine provides additional information, and influences therapeutic planning in HIV-positive patients with a $\mathrm{CD}_{4}$ cell count of less than $200 / \mu \mathrm{l}$ and GI-symptoms. This had therapeutic consequences in approximately $20 \%$ of the patients, when gastrointestinal symptoms were present. Thus, capsule endoscopy should be further evaluated in regard of its use for the management of HIV-infected patients with immunosuppression.

Acknowledgement: The study received funding by the Heinz Ansmann Foundation for AIDS-research.

Conflicts of interest: None to be declared.

\section{REFERENCES}

1. Poles MA, Barsoum S, Yu W, Yu J, Sun P, Daly J et al. Human immunodeficiency virus type 1 induces persistent changes in mucosal and blood gammadelta $\mathrm{T}$ cells despite suppressive therapy. J Virol 2003; 77:10456-10467.

2. Guadalupe M, Reay E, Sankaran S, Prindiville T, Flamm J, McNeil A et al. Severe $\mathrm{CD}_{4}+\mathrm{T}$-cell depletion in gut lympoid tissue during primary human immunodeficiency virus type 1 infection and substantial delay in restoration following highly active antiretroviral therapy. J Virol 2003; 77:11708-11717.

3. Veazey R, Lackner A. The mucosal immune system and HIV-1 Infection. AIDS Rev 2003; 5:245-252.

4. Monkemuller KE, Lazenby AJ, Lee DH, Loudon R, Wilcox CM. Occurence of gastrointestinal opportunistic disorders in AIDS despite the use of highly active antiretroviral therapy. Dig Dis Sci 2005; 2:230-234.

5. Forrest G. Gastrointestinal infections in immunocompromised hosts. Curr Opin Gastroenterol 2004; 20:16-21.

6. Goodgame RW. Gastrointestinal cytomegalovirus diease. Ann Intern Med 1993; 119:924-35.

7. Aragon TJ, Novotny $\mathrm{S}$ et al. Endemic cryptosporidiosis and expure to municipal tap water in persons with AIDS: a case control study. Public Health 2003; 3:2-12.

8. John P. Capsule endoscopy features of human immundeficiency virus and geograhical diseases. Gastrointest Endosc Clin N Am 14 (2004) 169-177.

Received: August 22, 2008 / Accepted: March 26, 2009

Address for correspondence:

Priv.-Doz. Dr. med. Mark Oette

Klinik für Allgemeine Innere Medizin, Gastroenterologie und Infektiologie

Krankenhaus der Augustinerinnen

Jakobstr. 27-31,

50678 Köln

Germany

E-mail: m.oette@koeln-kh-augustinerinnen.de 